\title{
A Genre Analysis of Popularization Articles on Autism in Science Daily
}

\author{
Ricardo Casañ Pitarch ${ }^{1}$ \\ Universitat Politècnica de València \\ Escuela Técnica Superior de Ingeniería Industrial $\cdot$ Universitat Politècnica de València $\cdot$ Camino de Vera, s/n $\cdot 46022 \cdot$ Valencia \\ (Spain) \\ Liliana Waicekawsky \\ Universidad de San Luis \\ Facultad de Humanidades · Av. Ejército de los Andes 950 - CP: $5700 \cdot$ San Luis (Argentina)
}

\section{ABSTRACT}

This paper analyzes the genre of popularization article discussing autism published by the magazine Science Daily. The objective of this research is to define this genre and describe its structure, language and most common features. The method applied involved the analysis of 50 samples of texts following the model proposed by Casañ-Pitarch (2016), and based on Bhatia (2004) and Swales (1990). Results suggest that there is a usual common structure among the texts of this genre and there are also some language forms that occur in most of the texts such as length, moves and steps, morphology, and the use of pronouns and verbs. In conclusion, after analyzing the results obtained from our corpus, some patterns have been suggested in order to define the most common structure and language forms within the genre of popularization articles published by Science Daily that discuss the topic of autism.

Keywords: Genre analysis, popularization articles, autism, Science Daily.

\section{RESUMEN}

Este artículo analiza el género de los artículos de divulgación sobre autismo publicados por la revista Science Daily. El objetivo de esta investigación es definir este género y describir su estructura, lenguaje y las características más comunes. El análisis incluye 50 muestras de textos siguiendo el modelo de Casañ-Pitarch (2016), este basado en Bhatia (2004) y Swales (1990). Los resultados sugieren que existe una estructura común entre los textos de este género y también hay algunas formas de lenguaje que aparecen en la mayoría de los textos, como la longitud, los contenidos, la morfología y el uso de pronombres y verbos. En conclusión, después de analizar los resultados obtenidos de nuestro corpus, se han sugerido una serie de patrones que definen la estructura y las formas de lenguaje más comunes dentro del género de artículos de divulgación publicados por Science Daily que tratan el tema del autismo.

Palabras clave: Análisis de género, artículos divulgativos, autismo, Science Daily.

\section{Introduction}

Reading science research papers could often become a difficult task for non-experts, despite their great willingness to understand the information and gain new knowledge. Sometimes, the general public prefers to read summaries or adapted scientific papers since the language used in them has been previously modified according to the type of readers who could be interested in those papers. Consequently, authors and editors of popularization articles should be completely aware of how to write them following the magazines' well-defined 
instructions on content, structure and forms. This practice was coined with the term Churnalism; and according to Johnston and Forde (2017), it was coined by Harcup in 2004, who defined it as "a form of journalism that relies on recycling press releases and agency copy and which involves little or no independent reporting or attempt at verification" (cited in Kristensen, 2018). In words of Johnston and Forde (2017: 943), this scientific genre describes "in less-than-complimentary terms the recycling process of news production which drew increasingly on wire service copy and public relations (PR) subsidies". Concerning the etymology of this word, Churnalism combines the terms churn and journalism and it implies the reuse of existing research material. The result of these articles is a brief summary of a previous research using suitable language for non-experts. For the interest of this research, Churnalism, a type of recycled and popularized documents, should be considered a particular genre. In this sense, genres are defined as "a recognizable communicative event characterized by a set of communicative purposes identified and mutually understood by members of the professional or academic community in which it regularly occurs" (Bhatia, 2013: 49); and they can be analyzed and defined. To this purpose, genre analysis is a field of applied linguistics which focuses on analyzing professional and academic documents with the aim of identifying text structures and language and forms and help users apply them into real contexts. In words of Bhatia (2004) the importance of these studies is the fact that they help communicators make the correct linguistic decisions such as the choice of lexicon and grammar in any rhetorical situations. Thus, genre analysis aims at reproducing specific discourse forms in any given context.

The objective of this research is to analyze and define the genre of popularization articles, more concretely those on the topic of autism and published in the magazine Science Daily. This article continues with the review of some literature related to defining this genre; then our method is detailed, and at last the results achieved are introduced and discussed. To fulfill the aim of this research, the following hypotheses have been stated:

H1- The texts corresponding to this genre shall follow a well-defined structure and common among the texts.

H2- The language used within this genre shall be formal and easy to read for a non-expert audience.

\section{Popularization articles}

Previous research describing features of popularization articles has been made (see De Avila and Torres, 2010; Myers, 2003; Nwogu, 1991; Seidel, 2016). Some of these researchers investigated the social and contextual properties of popular science texts, which are mainly associated to the fields of journalism and media or scientific communication (Alcibar, 2004). From a linguistic perspective, other researchers have also studied this genre and have analyzed its grammar, verbs usage, modality and hedging, or rhetorical structures, among others (see Myers, 2003; Calsamiglia, 2003; Ciaspucio, 1997). Following the findings of these previous researchers, it seems that this genre is characterized by features related to their audience, writers, publication format and specific communicative purposes, as it happens with other genres (Swales, 1990). These texts are generally addressed to non-specialist and broad audiences, and they are usually written by journalists and published in different outlets (Gotti, 2003; Peters, Kok, Crutzen, \& Sanderman, 2017). In addition, it also seems that the purpose of this type of document is to disseminate science and make specific knowledge comprehensible to an audience that is non-expert in the field and has some or little knowledge on the topic described (Edwards, 2015; Nguyen, 2014). Thus, this genre of popularization texts aims to inform their readers and extend their knowledge with findings that are novel to them (Diéguez Morales, 2005). Connected to popularization articles, it shall be noticed that a new tendency appeared in the early $20^{\text {th }}$ Century known as Churnalism. As it has been explained 
in the introduction, it recycles existing scientific articles and creates a new popularized version of them with the aim of communicating science to non-expert audiences (Johnston and Forde, 2017).

From a discourse study perspective, popular science writing has been approached from three broad areas. Calsamiglia (2003) explained that these three forms refer to the patterns of specific language and discourse used in different fields of science, the reinterpretation or reformulation of scientific content, and the micro-discourse features related to context, register, or text-type, among others. In addition, this genre of texts is also a valuable resource from a linguistic perspective because it provides deep insights that can be used in the language for specific purposes classroom.

In this research the main focus is placed on the genre of popularization article discussing the topic of autism and being published by the magazine Science Daily. Autism could be defined as "as a neuron-developmental disorder, characterized by repetitive stereotypic behaviors or restricted interests, social withdrawal, and communication deficits" (Sener, Uytun, Bayramov, Zararsiz, Oztop, Canatan, \& Ozkul, 2016: 613). The choice of this topic was made due to professional interest and related to the experience of the researchers of this paper. In this sense, it seems that popularization articles should follow the standard IMRC structure suggested by Swales (1990), which involves the moves of introduction, method, results, and conclusion. No specific information has been found on the steps within the previous moves in this particular field, but from a general perspective the introduction should contextualize the topic and set the research thesis as well as raising the audience's interest (McGaghie, Bordage \& Shea, 2001; Solar, 2013). Next, the method is the section describing the participants, materials, procedures and other information used during the research (Pyrczak, 2016). Meanwhile, the results section summarizes the data collected and explains the treatment of the data in basis to the hypotheses of the study (Singer, 1999). At last, the conclusion should provide the implications of the main findings and the perspectives of future research (Davidson \& Delbridge, 2012).

Regarding other elements that can be considered characteristic of popularization articles are its word category frequencies, including the use of pronouns and verbs, as well as their specific terminology. To this purpose, some literature related to these items has been previously published. For example, Fortanet-Gomez (2004) suggested that pronouns show how audiences are conceptualized by speakers; thus, the different choices can imply different perspective on individuals, things or facts. In the same way, Cangelosi and Parisi (2001) explained that verbs convey actions, and express states or relation among people or things; whereas Biber, Johansson, Leech, Conrad and Finegan (1999) explained at the same that time they control the focal point of the clause and they also influence the other elements. In addition, another feature of interest to this genre concerns reporting information, Bloch (2010) suggested a list with the most usual reporting verbs that could be used to use somebody else's information; his taxonomy shall be considered in this research. At last, regarding the word category frequencies of this genre, Heylighen and Dewaele's (1999) should be cited. They considered that the formality of a text is influenced by its word category frequencies. In this case, these authors classified words into formal (non-dependent: nouns, adjectives, prepositions, determiners) and deictic categories (dependent; pronoun, verb, adverb, interjections). Thus, the presence of nouns contrasting with a low degree of verbs would result in a high level of nominalization, whereas the opposite would imply more action and little focus on the description of facts. The first case would be more formal in written documents, whereas the second could be considered less formal and more usual in oral discourse. The degree of occurrence of the other remaining elements would also imply consequences within the text that will vary on the possible combinations. 


\section{Method}

This study aims at defining the genre of popularization article discussing the topic of autism in the magazine Science Daily, within the field of psychology. To this purpose a genre analysis was carried out following the model suggested by one of the authors in his previous research (Casañ-Pitarch, 2016). This model, at the same time, was based on Bhatia (2004) and Swales (1990). The corpus was formed by 50 articles published in the free-access magazine Science Daily dealing with the topic of autism from 2009 to 2017.

\begin{tabular}{ll}
\hline \multirow{2}{*}{ Macro-structure } & 1. Quantification of forms and structures - Wordsmith \\
& 2. Moves and steps forming the genre - none \\
\hline & 3. Morphology - TagAnt \\
4. Morphological Formality - TagAnt \\
Micro-structure & 6. Terminology - Tropes \\
& 7. Versonal pronoun - AntConc \\
\hline
\end{tabular}

Table 1. Analysis of multi-genre structures (Casañ-Pitarch, 2016)

The elements within the two broad categories in table 1 are the ones analyzed in this research. The macrostructure involved the analyses of the major structures and forms with the software Wordsmith as well as the moves and steps, which required a non-electronic analysis. On the other hand, after describing these previous elements, the research continued with the analysis of the micro-structure. This part of the analysis defined the language minor forms, including morphology, terminology, formality, personal pronouns as well as verbs and their tenses. In order to find the most usual form, the mean, median, mode and usual range of occurrence were considered. As it has been detailed in table 1, each item of the micro-structure was analyzed with specific software. In the case of verbs and their tenses, part of the analysis was carried with different software, but in the end it also required non-electronic checking. The analysis of the morphological formality was carried out applying the formula introduced by Heylighen and Dewaele's (1999). These authors classified words into formal (non-dependent) and deictic categories (dependent), as previously explained; and their formula was the following: ([noun\% + adjective\% + preposition \% + determiner\%]-[pronoun\% - verb\% - adverb\% - interjection\%] + 100)/2.

\section{Results}

\subsection{Macro-structure}

Our results have shown that the analyzed texts followed a well-defined pattern. These texts always began with the title of the article - mean: 9.76 words-; and they were rarely accompanied by subtitles (18\%), and whose mean length was 14 words. In addition, other items were always included in the top section of these popularization articles: date, source, and summary. The last of these had a mean extension of 49.20 words, and their content was the same or very similar to the one included in the next element, full story, which always appeared within this document and had a mean length of 53.26 words. Indeed, $46 \%$ of the summaries analyzed used the same words in their corresponding full story section. Their content mainly focused on introducing the main results achieved in their research (80\%); however, in fewer samples, authors also referred to a description of their experiments $(18 \%)$ or the method implemented $(6 \%)$. It shall be noticed that in most occasions only one of these steps was introduced (96\%), whereas two steps were combined in two articles. Furthermore, in order to 
complement this information, $28 \%$ of the full story sections included a picture with a brief description (mean: 26.36 words) and its source.

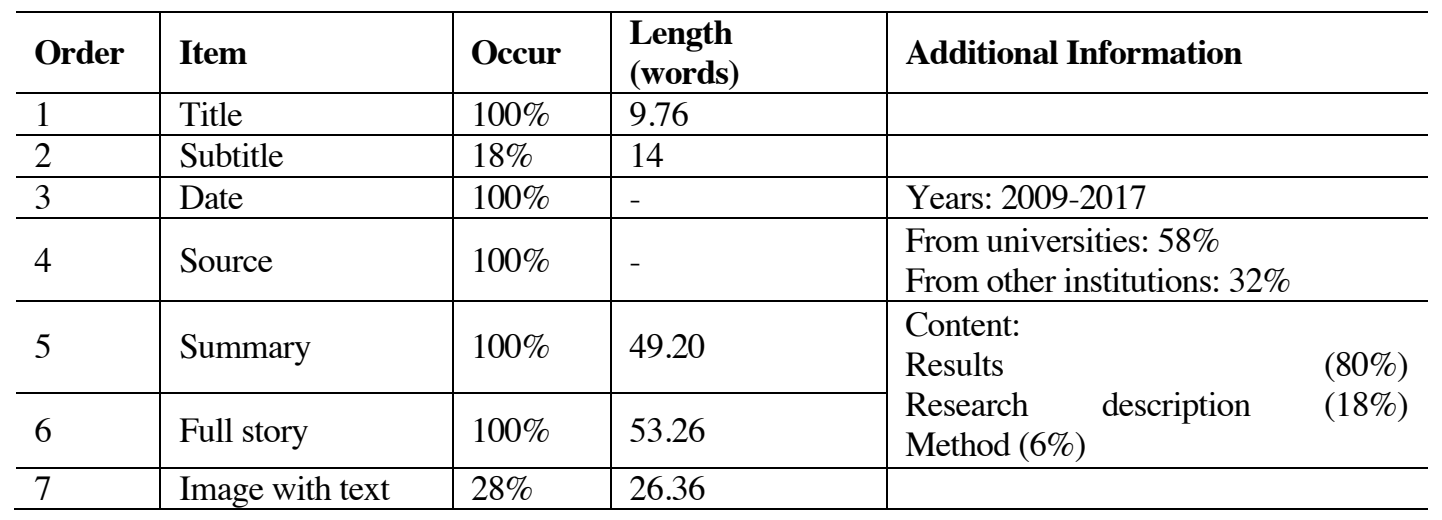

Table 2. Introductory Information

Regarding the main text, our first hypothesis suggested that the structure of popularization articles should be clearly-stated and common to all the texts; and in words of Swales (1990), it should be divided into introduction, body (method and results) and conclusion. Regarding this assertion, 98\% of the articles analyzed in this research followed that pattern. Only one text focused exclusively on results and showed a brief conclusion. Within the different moves of the text, our results also identified some steps. In this sense, introductions tended to contextualize the study with some literature, what had been done, or their objectives (68\%), but some also referred to the results obtained (28\%), or included some previous related research $(20 \%)$. We also found that $82 \%$ of the texts included one of these steps, whereas $16 \%$ of them covered two. Besides, results also suggested that the length of the introduction was $30.48 \%$ of the text. Concerning the body, the texts introduced a brief summary of the method (88\%) and the results obtained (90\%). These two steps were combined in $78 \%$ of the texts analyzed, whereas in the other $22 \%$ only one of them was shown. We also found that the extension of the method was $16.70 \%$ of the text, whereas the results covered $35.34 \%$ of the text length. At last, the conclusion involved two steps, implications of the results achieved (64\%) and further research (38\%). In this case, most texts only included one of these steps $(98 \%)$, whereas only one case included both (2\%). The extension of this last move was $17.47 \%$ of the text.

\begin{tabular}{|c|c|c|c|}
\hline Move & Steps & \multicolumn{2}{|l|}{ Length } \\
\hline Introduction & $\begin{array}{l}\text { Context: } 68 \% \\
\text { Previous Research: } 28 \% \\
\text { Results: } 20 \%\end{array}$ & \multicolumn{2}{|l|}{$30.48 \%$} \\
\hline Body & $\begin{array}{l}\text { Method: } 88 \% \\
\text { Results: } 90 \%\end{array}$ & $\begin{array}{l}16.70 \% \\
35.34 \%\end{array}$ & $52.04 \%$ \\
\hline Conclusion & $\begin{array}{l}\text { Implications: } 64 \% \\
\text { Further Research: } 38 \%\end{array}$ & \multicolumn{2}{|l|}{$17.47 \%$} \\
\hline
\end{tabular}

Table 3. Moves and steps

In addition to the analysis of moves and steps, a quantification of the forms was also made with the software Wordsmith. Our results showed that the average length of words in each text was 481.34. We also identified the median, 493, and the mode, 400-600 (44\%), as well as the longest text, 906, and the shortest one, 148. Regarding the amount of sentences, our results showed that the mean was 19.46 sentences per text. These sentences introduced a mean of 24.73 words in each sentence; furthermore, the largest amount of words per sentence was 
37.09, whereas the shortest one was 17.29. Our results also showed that the median compiled 25.15 words per sentence and the mode was the range between 23 and $28(48 \%)$. At last, our research found that there was a mean of 11.82 paragraphs per text. This also implied that the mean of sentences per paragraph was 1.65 , similar to the median, 1.67, and the mode, 1.50-2.00 (58\%). The text with largest amount of sentences per paragraph was 2.44 , and the shortest one contained 1.10 .

\begin{tabular}{l|l|l|l|l|l}
\hline Item & Mean & Median & Mode & Range & \\
\hline Words per text & 481.34 & 493 & $400-600(44 \%)$ & 148 & 906 \\
\hline Words per sentence & 24.73 & 25.15 & $23-28(48 \%)$ & 17.29 & 37.09 \\
\hline Words per paragraph & 38.80 & 41.79 & $35-45(56 \%)$ & 23.30 & 59.63 \\
\hline Sentences per text & 19.46 & 19 & $17-22(34 \%)$ & 6 & 40 \\
\hline Sentences per paragraph & 1.65 & 1.67 & $1.50-2.00(58 \%)$ & 1.10 & 2.44 \\
\hline Parragraphs per text & 11.82 & 12 & $10-15(52 \%)$ & 4 & 22 \\
\hline
\end{tabular}

Table 4. Quantification of forms

Finally, other elements identified within the samples of texts were also analyzed. After the main text, the document was always followed with information regarding the journal reference and information on how to cite this page. After these sections, the documents usually suggested some additional readings (98\%); they were entitled recommended articles (56\%) or related articles (42\%). Ten similar or related articles were suggested in the first case and four in the second case.

\subsection{Micro-structure}

The second part of our analysis focused on different elements that belong to the micro-structure of the texts. This part of our research involved the analysis of the word category frequencies in our corpus, morphological formality, terminology, use of pronouns and verbs. Our corpus contained 24,178 words corresponding to the main text of the 50 documents analyzed. Thus, this analysis did not consider titles, summaries, or other secondary sections.

To start with, the first element analyzed was the word category frequencies in our corpus. As it can be observed in table 5, the most usual category was the nouns (34.82\%), followed by prepositions (16.86\%), verbs (15.98\%), determiners (11.35), and adjectives (9.85\%). On the contrary, adverbs (4.37\%), connectors $(3.94 \%)$ and pronouns $(2.83 \%)$ occurred less often, whereas no interjections were found. In addition to these results, the formula introduced by Heylighen and Dewaele (1999) was applied in order to assess the morphological formality of the texts analyzed. This calculus resulted in a morphological formality degree of 74.98 .

\begin{tabular}{llllll}
\hline \multicolumn{2}{l}{ Formal Categories } & \multicolumn{4}{l}{ Deictic Categories } \\
\hline Noun & 8,418 & $34.82 \%$ & Verb & 3,863 & $15.98 \%$ \\
\hline Adjective & 2,382 & $9.85 \%$ & Pronoun & 684 & $2.83 \%$ \\
\hline Determiner & 2,745 & $11.35 \%$ & Adverb & 1,057 & $4.37 \%$ \\
\hline Preposition & 4,077 & $16.86 \%$ & Interjection & 0 & $0.00 \%$ \\
\hline Total & 17,622 & $72.88 \%$ & Total & 5,604 & $23.18 \%$ \\
\hline \multicolumn{2}{l}{ Morphological Formality: 74.85 } & & & \\
\hline \multicolumn{2}{l}{ Neutral Category } & & Connectors & 952 & $3.94 \%$ \\
\hline
\end{tabular}


Furthering our research on the word category frequencies in our corpus, we also analyzed the terminology fields within the texts analyzed using the software Tropes. As it can be observed in table 6 , there are 5 fields which seem to be the most relevant, and these are directly connected to the nature of the text as it was described in our theoretical framework. In addition, we also classified what we considered the most usual non-general nouns, adjectives and verbs according to the results provided by the same software. It could be observed that the most significant nouns were autism, children, study, disorder and researcher; whereas the most common adjectives were social, clinic, important, and genetic; similarly the most usual verbs were find, suggest, know, know, affect and identify. Results on specific terminology are shown in table 7.

Table 6. Terminology fields

\begin{tabular}{l|l|l|l|l|l}
\hline Field & Quant. & Field & \multicolumn{2}{l}{ Quant. } \\
\hline Health, life and casualties & 1,421 & $5.88 \%$ & Education and work & 271 & $1.12 \%$ \\
\hline Properties and characteristics & 863 & $3.57 \%$ & Behaviors and feelings & 250 & $1.03 \%$ \\
\hline General concepts & 776 & $3.21 \%$ & Politics and society & 227 & $0.94 \%$ \\
\hline Sciences and technology & 754 & $3.12 \%$ & Arts and culture & 218 & $0.90 \%$ \\
\hline People and persons & 745 & $3.08 \%$ & Countries and locations & 174 & $0.72 \%$ \\
\hline Numbers, time and dates & 289 & $1.20 \%$ & Communication and medias & 158 & $0.65 \%$ \\
\hline
\end{tabular}

\begin{tabular}{l|l|l|l|l|l}
\hline Nouns & Frequency & Adjectives & Frequency & Verbs & Frequency \\
\hline Autism & 326 & Social & 104 & Say & 163 \\
\hline Child(ren) & 281 & Clinic & 41 & Find & 62 \\
\hline Study(ies) & 195 & Important & 39 & Use & 61 \\
\hline Disorder(s) & 110 & Genetic & 38 & Show & 58 \\
\hline Researchers & 94 & Early & 33 & Suggest & 42 \\
\hline Behaviours & 78 & Different & 26 & Report & 31 \\
\hline Research & 75 & New & 26 & Know & 29 \\
\hline Brain & 72 & Specific & 24 & Make & 28 \\
\hline Parents & 67 & Intellectual & 24 & Affect & 27 \\
\hline
\end{tabular}

Table 7. Most usual non-general terminology

The following aspect that was considered in our research concerned the verbs and their use. In this sense, table 8 shows the most frequent tenses and verbal forms. As it can be observed, active present (30.42\%) and past simple tenses $(21.04 \%)$ were the most common verbal forms. In addition, the active voice $(64.29 \%)$ was also more common than the passive one (11.15\%) among finite verbs. On the other hand, the use of non-finite forms was $24.56 \%$; and within this category, the most usual ones were the infinitive as well as the present and past participle. Regarding the use of modal verbs, the software Tagant found 274, which represent the $7.09 \%$ of the verbs analyzed. Among them, the most usual ones were can (79), may (74), could (40), will (19), might (17) and should (15). No other modal verbs were found, only the forms of have to (5) and must (2) also occurred, but their presence seemed to be less relevant. At last, it was also found that most verbs had positive polarity $(97.83 \%)$, whereas only a few were negative $(2.17 \%)$.

\begin{tabular}{ll}
\hline Verbs Analyzed: $\mathbf{3 , 8 6 3}$ \\
\hline Tensed Verbs \\
\hline Active & Passive \\
\hline Pres. Simple: $30.42 \%$ & Pres. Simple:4.33\% \\
\hline Pres. Continuous: $2.03 \%$ & Pres. Continuous: $0 \%$ \\
\hline Pres. Perf. Simple: $3.45 \%$ & Pres. Perf. Simple: $1.06 \%$ \\
\hline Pres. Perf. Continuous: $0.09 \%$ & Pres. Perf. Continuous: $0 \%$ \\
\hline
\end{tabular}




\begin{tabular}{|c|c|c|}
\hline Active Present: $\mathbf{3 5 . 9 9 \%}$ & \multicolumn{2}{|c|}{ Passive Present: $5.39 \%$} \\
\hline \multicolumn{3}{|l|}{ Total Present: $41.38 \%$} \\
\hline Past Simple: $21.04 \%$ & \multicolumn{2}{|l|}{ Past Simple: $5.31 \%$} \\
\hline Past Continuous: $0.35 \%$ & \multicolumn{2}{|c|}{ Past Continuous: $0 \%$} \\
\hline Past Perf. Simple: $0.27 \%$ & \multicolumn{2}{|c|}{ Past. Perf. Simple: $0 \%$} \\
\hline Active Past: $21.66 \%$ & \multicolumn{2}{|c|}{ Passive Past: $5.31 \%$} \\
\hline \multicolumn{3}{|l|}{ Total Past: $26.97 \%$} \\
\hline \multicolumn{3}{|l|}{ Total Tensed Verbs: $68.35 \%$} \\
\hline Modal Verbs & Active & Passive \\
\hline Simple Modal & $6.45 \%$ & $0.45 \%$ \\
\hline Continuous Modal & $0.19 \%$ & $0 \%$ \\
\hline \multicolumn{3}{|l|}{ Total Modal Verbs: $7.09 \%$} \\
\hline \multirow{4}{*}{ TOTAL FINITE: $75.44 \%$} & \multicolumn{2}{|c|}{ TOTAL NON-FINITE: $24.56 \%$} \\
\hline & Infinitive: $8.43 \%$ & Pas. Infinitive: $1.24 \%$ \\
\hline & Pres. Part.: $8.43 \%$ & Past Part.: $6.02 \%$ \\
\hline & \multicolumn{2}{|l|}{ Imperative: $0.44 \%$} \\
\hline Positive Polarity: $97.83 \%$ & \multicolumn{2}{|c|}{ Negative Polarity: $2.17 \%$} \\
\hline
\end{tabular}

Table 8. Analysis of verbs

In addition to these results, it was also found that reporting verbs were frequent. Following the research carried out by Bloch (2010), we found that the texts contained 433 reporting verbs. This also corresponded to a high degree of direct quotations that the author of the articles used to refer to the original sources. The software AntConc found 250 direct quotations after introducing a specific formula in the search bar: "\.+?”. This implied a mean of 5 direct quotations per the text analyzed. The most usual reporting verbs were say (163), find (62), show (58), suggest (42), report (31), explain (12), and examine (10).

The last item considered in this research was the use of personal pronouns. Previously, table 5 showed that the amount of pronouns within the text analyzed was 684 . This analysis also found that 590 of these were personal pronouns, 2 of them were the pronoun one/s, and the remaining 92 were relative pronouns. Below, table 9 shows the amount of pronouns in each category. It can be observed that the most usual forms were we (119), they (110), it (69) and their (130). If we consider the different categories, these results showed that the ones most frequently used were subject pronouns (344) and possessive determiners (184). At last, the cases of the third person were the one that occurred more often (421) as well as the first one (165). Besides, it shall also be noticed that the plural forms (424) were more common than the singular ones (262).

\begin{tabular}{l|l|l|l|l|l|l}
\hline \multicolumn{2}{l|}{} & $\begin{array}{l}\text { Subject } \\
\text { Pronouns }\end{array}$ & $\begin{array}{l}\text { Object } \\
\text { Pronouns }\end{array}$ & $\begin{array}{l}\text { Possessive } \\
\text { Determiner }\end{array}$ & $\begin{array}{l}\text { Possessive } \\
\text { Pronouns }\end{array}$ & $\begin{array}{l}\text { Reflexive } \\
\text { Pronouns }\end{array}$ \\
\hline $\begin{array}{l}\text { First } \\
\text { Person }\end{array}$ & Singular & I (2) & Me (2) & My (2) & Mine & Myself \\
\cline { 2 - 7 } Second & Plural & We (119) & Us (14) & Our (25) & Ours (1) & Ourselves \\
\hline \multirow{3}{*}{$\begin{array}{l}\text { Third } \\
\text { Person }\end{array}$} & Singular/Plural & You (4) & You & Your & Yours & Yourself \\
\cline { 2 - 7 } & Fem. & She (25) & Her (2) & Her (8) & Hers & Herself \\
\cline { 2 - 7 } & Masc. & He (15) & Him (1) & His (2) & His & Himself \\
\cline { 2 - 7 } & Neut. & It (69) & It (13) & Its (17) & Its & Itself (4) \\
\hline
\end{tabular}

Table 9. Personal pronouns

\section{Discussion}

After the description of the results obtained in this research, this section discusses some common features of the genre of popularization articles on the topic of autism and published in the magazine Science Daily. As it has 
been explained, the aim of churnalism is to summarize scientific documents with specialized language and jargon and make them easy to read to a non-expert audience (Gotti, 2003; Peters, Kok, Crutzen, \& Sanderman, 2017). Having considered the results obtained, it seems that there are some common characteristics among the texts analyzed within this genre. In this sense, it shall be considered some usual features referring to both the macro and the micro-structure. The general structure of the text would correspond to the one suggested in figure 1. As it can be observed below, it includes all the sections analyzed except the subtitle and images, which were rarely found within the corpus. The sections that seem to form this document are title, date, source, summary, full story, main text, journal reference, cite this page, recommended articles (10) or related articles (4). As it was commented on the last item of the previous list, authors of this site could choose one form or the other indistinctively; their only difference was that the first one provided 10 articles whereas the second introduced 4. In addition to our proposed general structure of this genre, the quantification of forms also seems to have revealed that the length of the title should be approximately 10 words. Besides, the summary should contain about 45-50 words, and the full story should be a little longer and range between 50 and 55 words. Furthermore, in both cases, they should describe the results obtained in the original research. However, considering the similarity of the content introduced in these two sections, it would be advisable that editors of Science Daily clearly stated and distinguished the purpose of each category in their guidelines; and in case these were similar, we suggest that one of these sections should be removed.

\section{ScienceDaily}

Your source for the latest research news

TITLE (9-10 words)

Date: Month day, year

Source: University/Institution

Summary: $45-55$ words

Full story: $50-55$ words

(Main text: 450-550 words)

Introduction: 150 words

Method: 85 words

Results: 180 words

Conclusion: 85 words

\section{Story Source:}

Journal Reference:

Cite This Page:

Recommended Articles: 10 / Related Articles: 4

Figure 1. Pattern structure of the Magazine Daily Science

Next focusing on the main text of the article, we suggest that the introduction should contextualize the research using approximately 150 words. The body should be divided into two halves; the first would be the method applied in the research and its length should be about 85 words. Then, the body section should also be accompanied by the results obtained, and should contain around 180 words. At last, the conclusion should refer to the main implication of the research using approximately 85 words. Obviously, other options would also be 
possible despite most texts analyzed followed this pattern, and the mean, median and mode of our results tended to coincide.

In addition, it was also found that there were several paragraphs along the text and they contained few sentences. It was usual to find paragraphs with one single sentence, which contrasts with the most common form of academic documents (Swales, 1990). Based on our results, the texts should be formed by approximately 12 paragraphs. Besides, the amount of sentences per paragraph should be 1 and, in some cases, 2. In addition, concerning the amount of words per sentence, it should be approximately 25 words each. However, we believe that a better cohesion among sentences would be advisable, and consequently paragraphs should be longer as well. As result, it seems that the length of the texts, paragraphs and sentences in popularization articles is shorter than in the original scientific ones with the aim of disseminating science and making specific knowledge comprehensible to novel and non-expert audiences (Edwards, 2015; Nguyen, 2014).

Other details concerning the micro-structure were also considered. To start with, regarding morphology, there was a high degree and predominance of nouns, which implied a high degree of word nominalization. However, the degree of verbs was high, in comparison to our previous research, and this fact suggests continuous action within the text and discourse directness, as suggested by Heylighen and Dewaele (1999). In contrast, it seems that the amount of determiners and adjectives were low. This might suggest that the texts were not very descriptive and actions occurred regularly. Since this type of document is a summary, the authors focused more on action than on describing facts. In addition, these results concerning morphology also helped apply the formula introduced by Heylighen and Dewaele (1999) and obtain the degree of morphological formality within this genre. The result of 78.43 seems to be a reasonably high percentage in comparison to the examples these authors introduced in their work. This means that this type of document avoids the use of context dependent word categories and this implies formality despite the high degree of verbalization. These results lead again to the conclusion that the language register used in these articles needs to be neutral rather than scientific or academic.

Besides, a relevant amount of words should be related to the terminology field that they represent. In our case, the main topic was autism, within the field of psychology, and this implied that terminology within the text was related to health, life and casualties, properties and characteristics, and science and technology as well as general concepts. Besides, our results have also identified the most usual words that should be considered when developing the text. As result, it has been found some nouns such as autism, children, studies or disorder, adjectives including social, clinic, or genetic, verbs like say, find or use, which seem to be relevant within our corpus of texts. These words are obviously related to the field of research within this genre, but it seems that these usual words should sound familiar to most non-expert readers. This also implies that words have a neutral register.

Another aspect analyzed was the use of verbs. It could be stated that active present and past simple seem to be mandatory. These can be combined with infinitive and present and past participles, whereas the use of simple modal verbs was also common. Most part of the text had positive polarity, so negative forms should definitely be avoided. Concerning the verbs analyzed, it was also found that reported verbs occurred very often, especially to say, and as it was suggested by Bloch (2010). Furthermore, this also implied that direct quotations are often used to refer to the main article in an attempt to raise credibility. This seems to be common practice among these articles since they are a modified and summarized version of a previous one and need to prove their reliability. 
At last, the use of pronouns was also analyzed, despite their use was quite unusual along our corpus. Yet, it could be determined that some forms need to be taken into account, especially we, they, it and their. Relative and indefinite pronouns such as one were rare, and very few cases were found with the software AntConc. In words of Fortanet-Gomez (2004) pronouns conceptualized the audience; thus, the pronoun we imply the participation of all the members of a community and is inclusive. This personalization of the text is a characteristic of nonacademic texts and gives an idea of the intention of the author, who probably aims at approaching the reader, and this fact contrasts with the principles of academic texts, which avoid personalization of the information conveyed.

\section{Conclusion}

The aim of this paper was to analyze texts on the topic of autism, which were published in the magazine Science Daily. As it has been previously explained, these texts are popularization articles which belong to a genre known as Churnalism. The purpose of this type of magazines is to make scientific texts accessible to non-experts, making the language easier to understand and summarizing the content, only including the most relevant facts and findings. Results have shown that there are some common aspects among the different texts analyzed; and thus, they could be considered common to this genre. Our first hypothesis stated that the texts analyzed would follow a well-defined structure and common among the texts. As it has been shown, not all the texts follow the same structure but most of them did so. Regarding the second hypothesis, it seems that the language was formal (78.43), but also accessible and easy to read for a non-expert audience. It seems that this hypothesis can be confirmed after identifying the high degree of both nominalization and verbalization; furthermore, other features such as the use of the active voice, the type of terminology and the use of non-deictic categories made the texts easier to read for non-specialist readers. It seems that the authors of this type of articles clearly aim at disseminating science and making it comprehensible to non-expert audiences.

In further research, newer genres could be the focus of our study and in the same way other elements within this genre could also be considered such as syntax or speech acts. We consider that the use of 50 articles were sufficient to develop this research, despite it shall be acknowledged that a larger corpus would have been more relevant and reliable. At last, regarding some limitations, it shall also be acknowledged that this type of analysis could be more complete with syntax, semantic and pragmatic analysis, despite the real limitations on the development of suitable software that could carry out these actions.

\section{About the author}

Ricardo Casañ-Pitarch is a $\mathrm{PhD}$ assistant professor at the department of applied linguistics at UniversitatPolitècnica de València (Spain). He completed his education - Bachelor, Master, and PhD - at UniversitatJaume I in Castellón. His research interest is addressed to discourse analysis and language learning in the field of applied linguistics. More concretely, most of his work focuses on the analysis of language use and communication in virtual environments such as social networks, websites and mobile applications, as well as on the use of video games and technology for language learning and acquisition. 
Liliana Waicekawsky holds a position as an adjunct professor at the Institute of Languages at Universidad de San Luis (Argentina), where she teaches English for Specific Purposes. She obtained her Bachelor degree in Translation from Universidad Nacional de Córdoba and her Master's degree in Applied Linguistics from Universidad Nacional de Río Cuarto. She is also an EFL specialist. Her main research interests revolve around discourse analysis, systemic functional linguistics, appraisal theory and English for Specific Purposes. She is also interested in technology applied to education and in the field of corpus linguistics.

\section{References}

Alcíbar, M. (2004) La divulgación mediática de la ciencia y la tecnología como recontextualización discursiva. Anàlisi: Quaderns de comunicació i cultura, 31, 43-70.

Bhatia, V.K. (2004) Worlds of written discourse: a genre-based view. London: Continuum International.

Biber, D., Johansson, S., Leech, G., Conrad, S. and Finegan, E. (1999) Longman grammar of spoken and written English. London: Longman.

Bloch, J. (2010) A concordance-based study of the use of reporting verbs as rhetorical devices in academic papers, Journal of Writing Research, 2 (2), 219-244

Calsamiglia, H. (2003) Popularization discourse, Discourse Studies, 5 (2), 139-146.

Cangelosi, A. and Parisi, D. (2001) How nouns and verbs differentially affect the behavior of artificial organisms. In J. D. Moore and K. Stenning (eds.), Proceedings of the 23rd annual conference of the cognitive science society (pp. 170-175). London: Lawrence Erlbaum Associates.

Casañ-Pitarch, R. (2016) A proposal for genre analysis: The AMS model. In C. Vargas-Sierra (ed.), Professional and academic discourse: an interdisciplinary perspective (pp. 235-246). Manchester: Epic Series.

Ciapuscio, G. E. (1997) Lingüística y divulgación de ciencia, Quark: Ciencia, medicina, comunicación y cultura, 7 (1), $19-28$.

Davidson, A. and Delbridge, E. (2012) How to write a research paper, Paediatrics and Child Health, 22 (2), 61-65.

De Avila, P. and Torres, B. (2010) Introducing undergraduate students to science. Biochemistry and Molecular Biology Education, 38 (2), 70-78.

Diéguez Morales, M.I. (2005) Análisis contrastivo del anglicismo léxico en el discurso económico semiespecializado y de divulgación científica del español en Chile, Onomázein, 12, 129-156

Edwards, D.J. (2015) Dissemination of research results: on the path to practice change, The Canadian journal of hospital pharmacy, 68 (6), 465-469.

Fortanet-Gomez, I. (2004) The use of 'we' in university lectures: reference and function, English for Specific Purposes, 23 (1), 45-66.

Gotti, M. (2003) Specialized discourse: Linguistic features and changing conventions. Bern: Peter Lang.

Harcup, T. (2004) Journalism Principles and Practice. London: Sage.

Heylighen, F. and Dewaele, J.M. (1999) Formality of Language: Definition, Measurement and Behavioral Determinants. Brussels: Free University of Brussels.

Johnston, J. \& Forde, S. (2017) Churnalism. Digital Journalism, 5 (8), 943-946,

Kristensen, N. N. (2018) Churnalism, cultural (inter) mediation and sourcing in cultural journalism. Journalism Studies, 19(14), 21682186.

McGaghie, W., Bordage, G. and Shea, J.A. (2001) Problem statement, conceptual framework, and research question, Academic Medicine, 76 (9), 923-924.

Myers, G. (2003) Discourse studies of scientific popularization: Questioning the boundaries. Discourse studies, 5 (2), $265-279$.

Nguyen, D. (2014) Research Uptake: The value of effectively communicating research to your audience. European Scientific Journal, $10(10), 578-589$. 
Nwogu, K. N. (1991) Structure of science popularizations: A genre-analysis approach to the schema of popularized medical texts, English for Specific Purposes, 10 (2), 111-123.

Peters, G.Y, Kok, G., Crutzen, R. and Sanderman, R. (2017) Health Psychology Bulletin: improving publication practices to accelerate scientific progress, Health Psychology Bulletin, 1 (1), 1-6.

Pyrczak, F. (2016) Writing empirical research reports: A basic guide for students of the social and behavioral sciences. London: Routledge

Seidel, V. F. (2016) Funcionamento do gênero de divulgação científica: o tema do uso de animais não humanos em experimentos. PhD Dissertation, Universidade Federal do Rio Grande do Sul in Porto Alegre.

Sener, E., Uytun, M.C., Bayramov, K.K., Zararsiz, G., Oztop, D.B., Canatan, H., and Ozkul, Y. (2016) The roles of CC2D1A and HTR1A gene expressions in autism spectrum disorders, Metabolic brain disease, 31 (3), 613-619.

Singer, J. (1999) Using the American Psychological Association (APA) style guidelines to report experimental results, Proceedings of workshop on empirical studies in software maintenance (pp. 71-75).

Solar, I.J. (2013) Descripción funcional de introducciones de tesis doctorales en las disciplinas de química y linguistica, Onomázein: 28, 72-87.

Swales, J.M. (1990) Genre analysis: English in academic and research settings. Cambridge: Cambridge University Press. 